\title{
Refractive errors in children aged 6 to 8 years and associated factors. Cross-sectional analytical study
}

\section{Errores de refracción en niños de 6 a 8 años y factores asociados. Estudio transversal analítico}

\author{
Carlos J. Avendaño-Vásquez ${ }^{1 *}$, Jeimy N. Gutiérrez-Rodríguez², Javier A. Rodríguez-Hilarión ${ }^{1}$ and \\ Magda S. Ortiz-Clavijo ${ }^{3}$ \\ ${ }^{1}$ Faculty of Nursing; ${ }^{2}$ Faculty of Optometry; ${ }^{3}$ Faculty of Psychology. Universidad Antonio Nariño, Bogotá, Colombia
}

\begin{abstract}
Refractive errors (RE) have been of global interest because they are considered the most common ocular problem in all age groups. Recognizing its multifactorial character is vital to respond through prevention, diagnosis and timely treatment programs. Objective: To analyze the correlation between sociodemographic, nutritional, psychological and lifestyle factors with refractive errors in children. Methodology: Analytical cross-sectional study conducted on 149 children aged 6 to 8 years. Optometric assessment under cycloplegia, anthropometry and application of questionnaires regarding sociodemographic characteristics, lifestyles and personality. Results: The prevalence of hyperopia was $33.5 \%$ and of astigmatism $18.7 \%$, with an increase in the latter directly proportional to age. Children with hyperopia showed socially disadvantaged conditions (52\%). No statistically significant differences were observed regarding nutritional status, but there was a correlation with the consumption of foods such as sugars and dairy products ( $p=0.030$ and $p=0.017$, respectively). Risk factors such as exposure to tobacco or alcohol consumption were identified in $14.1 \%$ of emmetropic children. Hyperopic children showed lower capacities regarding statistically significant safety and doubt scales $(p=0.017)$ compared to emmetropic and hyperopic children. Conclusion: Children with hyperopia showed more risk factors related to lifestyle and personality traits. The growing tendency of astigmatism in our study population should drive early intervention measures to reduce its impact on the school context. Longitudinal studies are suggested that include modifiable behavior patterns to evaluate statistical significance.
\end{abstract}

Key words: Refractive errors. Hyperopia. Astigmatism. Children. Healthy lifestyles. Personality determination. Nutritional status.

\section{Resumen}

Los errores de refracción (ER) han sido motivo de interés mundial por ser considerados el problema ocular más común en todos los grupos de edad. Reconocer su carácter multifactorial es vital para dar respuesta a través de programas de prevención, diagnóstico y tratamiento oportuno. Objetivo: Analizar la asociación de ER con factores sociales, nutricionales, psicológicos y estilos de vida en niños de 6 a 8 años. Método: Estudio transversal analítico realizado a 149 niños de 6 a 8 años. Valoración de optometría bajo cicloplejia, antropometría y cuestionarios de características sociodemográficas, estilos de vida y personalidad fueron aplicados. Resultados: La prevalencia de hipermetropía fue del 33,5\% y de astigmatismo

Correspondence:

${ }^{*}$ Carlos J. Avendaño-Vásquez

Universidad Antonio Nariño, Facultad de Enfermería

Carrera 3 este \# 47a-15

Date of reception: 19-08-2019

Date of acceptance: 06-05-2020

E-mail: cjavasquez@uan.edu.co (http://creativecommons.org/licenses/by-nc-nd/4.0/). 
del $18,7 \%$, con un incremento de este último directamente proporcional a la edad. Niños con hipermetropía mostraron condiciones socialmente menores (52\%). No se hallaron diferencias estadísticamente significativas en relación con el estado nutricional, pero sí con el consumo de alimentos como azúcares y lácteos ( $p=0,030$ y $p=0.017$, respectivamente). Factores de riesgo como exposición a tabaco o consumo de alcohol fueron identificados en el $14.1 \%$ de niños emétropes. Los niños hipermétropes mostraron menores capacidades frente a escalas de seguridad y duda estadísticamente significativas $(p=0.017)$ en comparación con niños emétropes y con astigmatismo. Conclusion: Los niños con hipermetropía demostraron mayores factores de riesgo relacionados con estilos de vida y rasgos de personalidad. La tendencia creciente de astigmatismo en nuestra población de estudio sugiere medidas de intervención precoces para disminuir su impacto en el contexto escolar. Se sugieren estudios longitudinales que contemplen patrones de conducta modificables para hallar significancia estadística.

Palabras clave: Errores de refracción. Hiperopía. Astigmatismo. Niño. Estilos de vida saludable. Determinación de la personalidad. Estado nutricional.

\section{Introduction}

Refractive errors (RE) have been of global interest as they are considered the most common ocular problem in all age groups, due to their impact on visual loss and healthcare costs, which produce an annual loss of 269 billion dollars ${ }^{1}$. The etiology of RE in children has been attributed to sociodemographic factors such as age, sex, race, and educational level; and to lifestyles, including physical activity, nutrition, exposure to toxins, sleep patterns and general health. On the other hand, some studies have also linked RE with the expression of personality traits and emotional state ${ }^{2-6}$, with the aim of analyzing the multidimensionality of this condition and answering the questions that arise as the life patterns of the population modify, for the creation of programs with an impact on the prevalence and incidence of $\mathrm{RE}$, which are already considered a public health problem. In this sense, making an early diagnosis of $\mathrm{RE}$ and intervening in a timely manner the factors that affect its etiology can improve the visual health of the child population, and it is of utmost importance to respond to programs aimed at reducing gaps in the prevention, detection and care of $R E^{1,7,8}$.

According to the World Health Organization (WHO), " $80 \%$ of the causes of visual impairment are preventable or curable" of age is a special priority, due to the possibility of implementing effective interventions and preventing unfavorable implications in their development, access to education, learning and, therefore, the quality of life of children ${ }^{10}$. Although in Colombia and other Latin American countries there are few reports of prevalence studies, some research supports an increase in myopia, with great variation according to age, ethnicity and sociodemographic factors, and a stable behavior in the case of hyperopia and astigmatism in the last 40 years ${ }^{7,11}$. In this sense, research on the epidemiological behavior of RE is increasing, but its evaluation, regarding social or psychological causes, is still emerging.

In this context, and according to the WHO, visual health must "be integrated into broader frameworks on non-communicable and communicable diseases", which implies the need to carry out inter-professional studies in the framework of prevention in children, to intervene from different perspectives on the main causes, recognizing the multifactorial etiology of $\mathrm{RE}^{12}$ and contributing to health care initiatives in later stages of life and in marginalized and vulnerable groups.

Under these statements, this study is presented as one of the first to perform an analysis of RE in school children with the aim of analyzing its relationship with lifestyles and personality traits, making an approximation of their prevalence and manifestation derived from psychosocial conditions of Colombian boys and girls, as a contribution to the recognition of RE from a comprehensive and multidisciplinary perspective.

\section{Objective}

To analyze the correlation of RE with social, nutritional, psychological and lifestyle factors in children from 6 to 8 years of age.

\section{Methods}

\section{Study design and participants}

Analytical cross-sectional study, carried out on 149 children between the ages of 6 and 8 during the second semester of 2018, from two sites of a public educational institution, located in the town of Ciudad Bolívar in the city of Bogotá, Colombia, characterized by marginalized population states. A simple random sampling was 
performed in a universe of 235 children, taking the reported prevalence for astigmatism of $27.2 \%$ as the anticipated frequency, which is defined as the RE with the highest frequency in 2018 in the American continent ${ }^{1}$. The study applied a confidence rate of $95 \%$ and a standard error of $5 \%$. Informed consent was obtained from the primary caregiver and informed assent from the children. Exclusion criteria were children with cognitive deficits or with previous ocular diseases.

\section{Procedures and instruments}

Refractive examination was performed following the protocol of the Iberoamerican Epidemiological Network on Visual and Ocular Health that establishes the application of a drop of benoxinate $0.4 \%$, a drop of tropicamide $1 \%$ and a drop of cyclopentolate $1 \%$ (with an administration interval of 1 to 5 minutes between each drop). Subsequently, after 30 minutes, the pupillary diameter was assessed expecting a dilation greater than or equal to $6 \mathrm{~mm}$ in diameter and a negative pupillary reaction to light, at which time the refraction of each of the children was determined.

The diagnosis of RE was made according to the assessment of refractive errors in children ${ }^{13}$ and the Clinical Practice Guideline for the early detection, diagnosis, treatment, and monitoring of refractive defects in children under 18 years of age in Colombia ${ }^{10}$.

For the definition of ametropia under cycloplegia, the spherical equivalent (SE) was used, calculated as the value of the sphere plus half of the cylinder, and that the latter is not greater than 0.50 diopters (D), to define emmetropia, hyperopia, myopia and astigmatism. Emmetropia was defined as a SE between $-0.25 \mathrm{D}$ and $+1.75 \mathrm{D}$; hyperopia as a $\mathrm{SE} \geq+2.00 \mathrm{D}$; myopia as a SE $\leq-0.50 \mathrm{D}$, and astigmatism was defined considering a cylinder with a value greater than or equal to one third of the sphere, positive or negative.

The anthropometric classification of nutritional status was made following the anthropometric indicators, the reference standards and the cut-off points for children and adolescents established by the Ministry of Health and Social Protection of Colombia, which, in turn, are based on the recommendations established by the WHO in nutritional matters worldwide ${ }^{14}$.

The indicator and the cut-off point established by the standard deviation (SD) were used for the anthropometric classification of the nutritional status of the children. For the height-for-age indicator $(\mathrm{H} / \mathrm{A}), \mathrm{SD} \geq-1$ (appropriate height for age); $S D \geq-2$ to $<-1$ (risk of delayed growth); SD $<-2$ (short height for age or delayed growth). For the body mass index-for-age indicator (BMI/A), SD > +2 (obesity); $S D>+1$ to $\leq+2$ (overweight); $S D \geq-1$ to $\leq+1$ (normal BMl for age); $S D \geq-2$ to $<-1$ (risk of undernourishment) and $S D<-2$ (undernourished) ${ }^{14}$.

For weight measurements, a previously calibrated scale with a maximum capacity of $150 \mathrm{~kg}$, with a digital mechanism and a precision of $50 \mathrm{~g}$ was used. The scale was placed on a flat surface and the measurement was taken with the child standing with the least clothing possible. The weight was measured in two time-points to validate the sensitivity of the scale. To measure height, a portable height rod with a maximum capacity of $2 \mathrm{~m}$ and a sensitivity of $1 \mathrm{~mm}$ was used, which was fixed with screws to the wall. The measurement was taken twice and was repeated in cases with a variability greater than 0.5 centimeters $(\mathrm{cm})^{14}$.

Sociodemographic data were obtained through a survey of the social and economic conditions of the population, which contained questions about food consumption and sleep and rest habits. To identify healthy lifestyles, we used the FANTASTIC instrument adapted to the Colombian population by Betancurth, et al. in $2015^{15}$. This instrument is made up of 30 questions that integrate 10 dimensions: F: family and friends, A: physical and social activity, N: nutrition, T: toxicity A: alcohol, S: sleep and stress, T: personality type and activities, I: inner image, C: health and sexuality control and, finally, O: order. Each dimension has answer options with a numerical value from 0 to 2 , and they are scored using a Likert-type scale. The instrument score ranges from 0 to 120 points; the higher the dimension score, the more positive the score is compared to the habits and customs related to a healthy lifestyle ${ }^{15}$.

The psychological profile of the children was evaluated using the ESPQ Children's Personality Questionnaire, prepared by Coan and Cattell in 1966 and adapted to Spanish by TEA Ediciones in 1998. The questionnaire is aimed at children between 6 and 8 years old that attend the first, second and third grades of primary basic education. The questionnaire consists of 160 questions that measure 13 first-order personality factors, which are: factor $A$ (reserved-open), factor B (low-high intelligence), factor $C$ (affected by feelings-emotionally stable), factor $D$ (calm-excitable), factor $E$ (submissive-dominant), factor $F$ (sober-enthusiastic), factor $G$ (carefree-careful), factor $\mathrm{H}$ (shy-outgoing), factor I (soft sensitivity-hard sensitivity), factor $\mathrm{J}$ (self-assured-hesitant), factor $\mathrm{N}$ (simple-clever), factor $\mathrm{O}$ (serene-apprehensive) and factor Q4 (relaxed-tense). It also measures 
2 second-order personality factors: QI (flexible-anxiety) and QII (introversion-extraversion) ${ }^{16}$.

It was administered to the population of the study collectively in two stages, according to the recommendations of the test manual. Taking into account the purpose of the research, 8 of the 13 first-order factors (A, D, E, F, H, J, O, Q4) were chosen considering that the influence of RE could be identified in this personality traits, based on personality theories related to behavior patterns that are determined by the influence of the environment on people's daily interaction ${ }^{16}$.

\section{Statistical analysis}

This study excluded myopia data because there was only one case; therefore, all variables analyzed were related to emmetropia, hyperopia and astigmatism. Simple and relative frequencies, mean (M) and SD were used for the presentation of descriptive data. The association between growth patterns, nutritional habits and RE was evaluated using the ANOVA test of variance. The lifestyle results were presented using descriptive statistics and graphically summarized. To establish the association between personality traits and $\mathrm{RE}$, we used the ANOVA test of variance based on the results of each decatype by scale and second-order factors. Decatypes are distributed on a 10-point scale equidistant in typical units, with a mean of 5.5 and a SD of 2 decatypes. Thus, values of 5-6 were considered within the mean of the population mean, and the values between 2-3 and 8-9 were considered with a great deviation, while the values of 1 and 10 were considered as extreme deviations.

Finally, the variables related to nutritional diagnosis, lifestyles, and personality traits were categorized to establish an association with RE using the Pearson's Chi-square test, expressing the data according to the result of $p$ significance. The level of significance established for this study was $p<0.05$. The statistical analysis was performed using the SPSS 25 software.

\section{Ethical considerations}

This study adheres to the guidelines for research in humans in accordance with the World Medical Association and the Declaration of Helsinki; and by the Resolution 8430 of 1993 of the Ministry of Health of the Republic of Colombia that establishes the considerations related to the investigation in adults and minors. The study was approved by the Ethics Committee of the Antonio Nariño University in the city of Bogotá,
Colombia, under protocol number 2017226. Likewise, it was presented and approved by the directives of a school located in the town of Ciudad Bolívar in Bogotá. The data collection procedures were carried out with the prior informed consent of parents and caregivers and the informed assent of children with literacy skills.

\section{Results}

The population was evaluated in the second semester of 2018. Sixty-four girls and 85 boys participated in the study, without exclusions due to ethnic origin; the majority were enrolled in second grade of primary school. As for the sociodemographic characteristics, the socioeconomic conditions of the population stand out due to low levels of economic income and social stratification; likewise, the educational level of the majority of parents and caregivers does not exceed secondary education.

Regarding the diagnosis of RE, we observed a prevalence of $33.5 \%$ of hyperopia and $18.7 \%$ of astigmatism, with a greater frequency of hyperopia in boys and of astigmatism in girls. On the other hand, significant differences were observed between the diagnosis of $R E$ and the school grade $(p<0.05)$, based on a higher frequency of astigmatism with increasing grades, and an inverse behavior regarding hyperopia; subsequently, this behavior is the same in relation to age.

Data related to social aspects, such as family income, social status or family educational level, did not show statistically significant differences, but they did show a greater frequency of hyperopia in lower socioeconomic conditions compared to emmetropic children and children with astigmatism (Table 1).

Regarding growth patterns and nutritional habits, greater weight and height were observed in emmetropic children ( $\mathrm{M}=26.58 \pm 5.96 ; 1.25 \pm 0.06)$ compared to boys and girls with hyperopia $(\mathrm{M}=24.30 \pm 4.84$; $1.21 \pm 0.07)$ and astigmatism $(M=25.02 \pm 3.79 ; 1.24$ \pm 0.06 ), and statistically significant differences were observed using height as an indicator of cumulative nutritional status $(p=0.046)$. However, the results versus the global indicator of overweight or malnourishment, given by the BMI, did not show statistically significant differences between children compared by RE.

The consumption habits of healthy foods such as vegetables and fruits, in general, did not exceed two daily servings, with the exception of dairy consumption, identifying a greater consumption in children with hyperopia that was statistically significant (Table 2). On the other hand, the consumption of unhealthy foods, 
Table 1. Sociodemographic characteristics and refractive errors of the population (Bogotá, Colombia; $n=149$ )

\begin{tabular}{|c|c|c|c|c|c|c|c|}
\hline & Emmetropia & Hyperopia & Astigmatism & & Emmetropia & Hyperopia & Astigmatism \\
\hline & $n(\%)$ & $n(\%)$ & $n(\%)$ & & $n(\%)$ & $n(\%)$ & $n(\%)$ \\
\hline Sex & & & & Social stratum & & & \\
\hline Female & $29(40.8)$ & $20(40.0)$ & $15(53.6)$ & Low-low & $30(42.3)$ & $26(52.0)$ & $16(57.1)$ \\
\hline Male & $42(59.2)$ & $30(60.0)$ & $13(46.4)$ & Low & $40(56.3)$ & $24(48.0)$ & $12(42.9)$ \\
\hline Grade & & & & Medium-low & $1(1.4)$ & 0 & 0 \\
\hline First & $11(15.5)$ & $29(58.0)$ & $7(25.0)$ & Mother's educational level & & & \\
\hline Second & $31(43.7)$ & $20(40.0)$ & $10(35.7)$ & None & $1(1.4)$ & 0 & 0 \\
\hline Third & $29(40.8)$ & $1(2.0)$ & $11(39.3)$ & Primary & $7(9.9)$ & $5(10.0)$ & $4(14.3)$ \\
\hline Age (years) & & & & Secondary & $42(59.2)$ & $32(64.0)$ & $13(46.4)$ \\
\hline 6 & $3(4.2)$ & $15(30.0)$ & $2(7.1)$ & Technician & $16(22.5)$ & $11(22.0)$ & $7(25.0)$ \\
\hline 7 & $25(35.2)$ & $24(48.0)$ & $10(35.7)$ & University & $5(7.0)$ & $2(4.0)$ & $4(14.3)$ \\
\hline 8 & $42(59.2)$ & $11(22.0)$ & $15(53.6)$ & Father's educational level & & & \\
\hline 9 & $1(1.4)$ & 0 & $1(3.6)$ & None & $4(5.6)$ & $1(2.0)$ & 0 \\
\hline Family income & & & & Primary & $7(9.9)$ & $12(24.0)$ & $3(10.7)$ \\
\hline Less than 1 SMMLV* & $7(9.9)$ & $12(24.0)$ & $5(17.9)$ & Secondary & $50(70.4)$ & $30(60.0)$ & 18 (64.3) \\
\hline Between 1 and 2 SMMLV & $55(77.5)$ & $27(54.0)$ & $20(71.4)$ & Technician & $5(7.0)$ & $4(8.0)$ & $5(17.9)$ \\
\hline Between 2 and 3 SMMLV & $7(9.9)$ & $8(16.0)$ & $2(7.1)$ & Technologist & 0 & $2(4.0)$ & 0 \\
\hline More than 3 SMMLV & $2(2.8)$ & $3(6.0)$ & $1(3.6)$ & University & $5(7.0)$ & $1(2.0)$ & $2(7.1)$ \\
\hline
\end{tabular}

*SMMLV: current legal monthly minimum wage for Colombia COP 828.116 .

such as packaged and fast food is low, and is limited to less than one consumption per week in the case of fast food and one serving of packaged food per day. Even so, statistically significant differences were identified in the consumption of sugary drinks between children with RE and emmetropic children, which was lower in the latter.

On the other hand, the study showed statistically significant differences between the children's average hours of sleep compared by RE, and the sleep time was greater in children with hyperopia compared to the other two study groups (Table 2).

The lifestyle of the boys and girls participating in the study, in general, showed a positive behavior in most of the dimensions analyzed. The communication and expression of affection skills of the children showed results above $50.7 \%$, and the reception of affection from parents and caregivers was perceived with ranges higher than $72 \%$, giving an overall high score.

Regarding food, more than $40 \%$ of children reported access to varied and healthy food, and consumption of breakfast, brunch and lunch in $88 \%$ of cases. On the other hand, the consumption of unhealthy foods was restricted to a weekly or biweekly frequency in $76.1 \%$ of the population.

Exposure to toxins and alcohol was limited, and the trend yielded a positive response; however, it was related as a risk factor in the study population. It was identified that $14.1 \%$ of emmetropic children had smoked and $5.6 \%$ had ever consumed alcohol. This can be related to living with people with constant alcohol or cigarette consumption, which was $11.3 \%$ in emmetropic children compared to hyperopic children and children with astigmatism (2 and 10.7\%, respectively).

Sleep habits, in general, showed that the perception of rest for all children is above $62 \%$, and the dimensions related to personality type and inner image showed an adequate management of stressful situations, ability to relax, emotional stability and good humor. Even so, it was possible to determine that children with hyperopia have a greater dissatisfaction with studying $(51.4 \%)$ compared to emmetropic children 
Table 2. Refraction errors and growth patterns, nutritional, sleep and reading habits

\begin{tabular}{|c|c|c|c|c|c|c|c|c|c|c|}
\hline & \multicolumn{3}{|c|}{ Emmetropia (n= 71) } & \multicolumn{3}{|c|}{ Hyperopia (n= 50) } & \multicolumn{3}{|c|}{ Astigmatism (n= 28) } & \multirow[t]{3}{*}{ p-value* } \\
\hline & \multirow[t]{2}{*}{ M/SD } & \multicolumn{2}{|c|}{$95 \% \mathrm{Cl}$} & \multirow[t]{2}{*}{ M/SD } & \multicolumn{2}{|c|}{$95 \% \mathrm{Cl}$} & \multirow[t]{2}{*}{ M/SD } & \multicolumn{2}{|c|}{$95 \% \mathrm{Cl}$} & \\
\hline & & $\begin{array}{c}\text { Lower } \\
\text { limit }\end{array}$ & $\begin{array}{l}\text { Upper } \\
\text { limit }\end{array}$ & & $\begin{array}{c}\text { Lower } \\
\text { limit }\end{array}$ & $\begin{array}{l}\text { Upper } \\
\text { limit }\end{array}$ & & $\begin{array}{c}\text { Lower } \\
\text { limit }\end{array}$ & $\begin{array}{c}\text { Upper } \\
\text { limit }\end{array}$ & \\
\hline Weight (kg) & $26.58 \pm 5.96$ & 25.176 & 28.001 & $24.3 \pm 4.84$ & 22.924 & 25.676 & $25.02 \pm 3.79$ & 23.549 & 26.494 & 0.056 \\
\hline Height (m) & $1.25 \pm 0.06$ & 1.240 & 1.272 & $1.21 \pm 0.07$ & 1.197 & 1.238 & $1.24 \pm 0.06$ & 1.221 & 1.271 & 0.009 \\
\hline BMI & $16.71 \pm 2.67$ & 16.080 & 17.347 & $16.28 \pm 2.17$ & 15.666 & 16.900 & $16.06 \pm 1.70$ & 15.407 & 16.732 & 0.396 \\
\hline Fruit servings per day & $1.61 \pm 0.93$ & 1.399 & 1.840 & $1.62 \pm 1.10$ & 1.306 & 1.934 & $1.64 \pm 1.47$ & 1.072 & 2.213 & 0.995 \\
\hline Vegetable servings per day & $1.12 \pm 0.84$ & 0.927 & 1.327 & $1.28 \pm 0.90$ & 1.023 & 1.537 & $1.32 \pm 1.18$ & 0.861 & 1.782 & 0.541 \\
\hline Sugary drinks per day & $0.88 \pm 0.85$ & 0.685 & 1.090 & $1.56 \pm 1.97$ & 1.000 & 2.120 & $1 \pm 1.24$ & 0.516 & 1.484 & 0.030 \\
\hline Dairy servings per day & $1.94 \pm 1.18$ & 1.664 & 2.223 & $2.48 \pm 1.44$ & 2.069 & 2.891 & $1.71 \pm 1.01$ & 1.321 & 2.107 & 0.017 \\
\hline Packaged food per day & $1.18 \pm 1.00$ & 0.945 & 1.421 & $1.04 \pm 0.94$ & 0.771 & 1.309 & $1.25 \pm 0.96$ & 0.875 & 1.625 & 0.606 \\
\hline Fast food per week & $0.59 \pm 0.70$ & 0.424 & 0.759 & $0.72 \pm 0.92$ & 0.457 & 0.983 & $0.42 \pm 0.50$ & 0.233 & 0.624 & 0.265 \\
\hline Sleep hours per day & $8.63 \pm 0.97$ & 8.403 & 8.864 & $9.04 \pm 1.08$ & 8.731 & 9.349 & $8.46 \pm 1.03$ & 8.063 & 8.866 & 0.032 \\
\hline PC or TV hours during the week ${ }^{\dagger}$ & $2.81 \pm 3.15$ & 2.070 & 3.564 & $3.88 \pm 2.25$ & 3.239 & 4.521 & $2.5 \pm 2.78$ & 1.421 & 3.579 & 0.057 \\
\hline PC or TV hours during weekends ${ }^{\dagger}$ & $3.35 \pm 2.71$ & 2.711 & 3.994 & $3.6 \pm 3.30$ & 2.660 & 4.540 & $2.75 \pm 3.05$ & 1.567 & 3.933 & 0.482 \\
\hline $\begin{array}{l}\text { Reading or drawing during the } \\
\text { week }^{\dagger}\end{array}$ & $2.09 \pm 2.06$ & 1.610 & 2.587 & $2.56 \pm 2.74$ & 1.781 & 3.339 & $2.25 \pm 1.77$ & 1.561 & 2.939 & 0.545 \\
\hline $\begin{array}{l}\text { Reading or drawing during } \\
\text { weekends }^{\dagger}\end{array}$ & $1.90 \pm 1.63$ & 1.515 & 2.288 & $2.52 \pm 1.84$ & 1.996 & 3.044 & $1.92 \pm 1.80$ & 1.229 & 2.628 & 0.132 \\
\hline $\begin{array}{l}{ }^{*} \text { ANOVA. } \\
{ }^{+} \text {Average in hours. } \\
\mathrm{p}<0.005 \text { value with statistical significance. } \\
\mathrm{M} / \mathrm{SD} \text { : mean and standard deviation. }\end{array}$ & & & & & & & & & & \\
\hline
\end{tabular}

(37.8\%) and to children with astigmatism (10.8\%), with statistically significant differences $(p=0.046)$. Emotions such as stress were minimally perceived, but feelings of sadness were perceived in a higher percentage in children with hyperopia $(66.7 \%)$ compared to the other two groups (emmetropia $22.2 \%$, astigmatism $11.1 \%$ ).

Finally, an irregular trend in the medical control and sexuality care was identified in all boys and girls, with dissatisfaction regarding perception of physical appearance in $52 \%$ of children with hyperopia, a percentage higher than the rest, which is reflected in the overall trend of the dimension. Limited participation in social and recreational activities stands, considering that $57.1 \%$ of boys and girls never participated in youth activities or did scheduled physical exercise. Figure 1 shows the global trends of the lifestyle dimensions evaluated, and mainly reflects the negative impact on the overall result of social activities and physical exercise, and health care in the lifestyle of boys and girls. (Fig. 1).

The results of the personality traits of the participating boys and girls showed evidence of average abilities for the control of anxiety (QI factor), reflecting personality stability. The scales that make up this factor showed the same trend compared to the population mean on scales $D, F, H, O$ and $Q 4$, reflecting children who have normal reactions to stimuli, from a relatively safe family environment, with a positive emotional response towards people, expressive and active, few apprehensive and with positive sociability behaviors. However, statistically significant differences were identified on the $\mathrm{J}$ scale between children with astigmatism and children with hyperopia, the latter had (according to the most individualistic scale criteria) motor repression and were disdainful with others, compared to children with $\mathrm{J}$-.

Factor QII of introversion-extraversion is represented by the scales A, E, F, and Q4, which also showed average results versus the population mean, and reflected that children adapted to the school environment, with positive, constructive behaviors and an adequate family environment (Table 3).

Finally, Table 4 shows the results of the association analysis between categorized variables and RE. Most of 


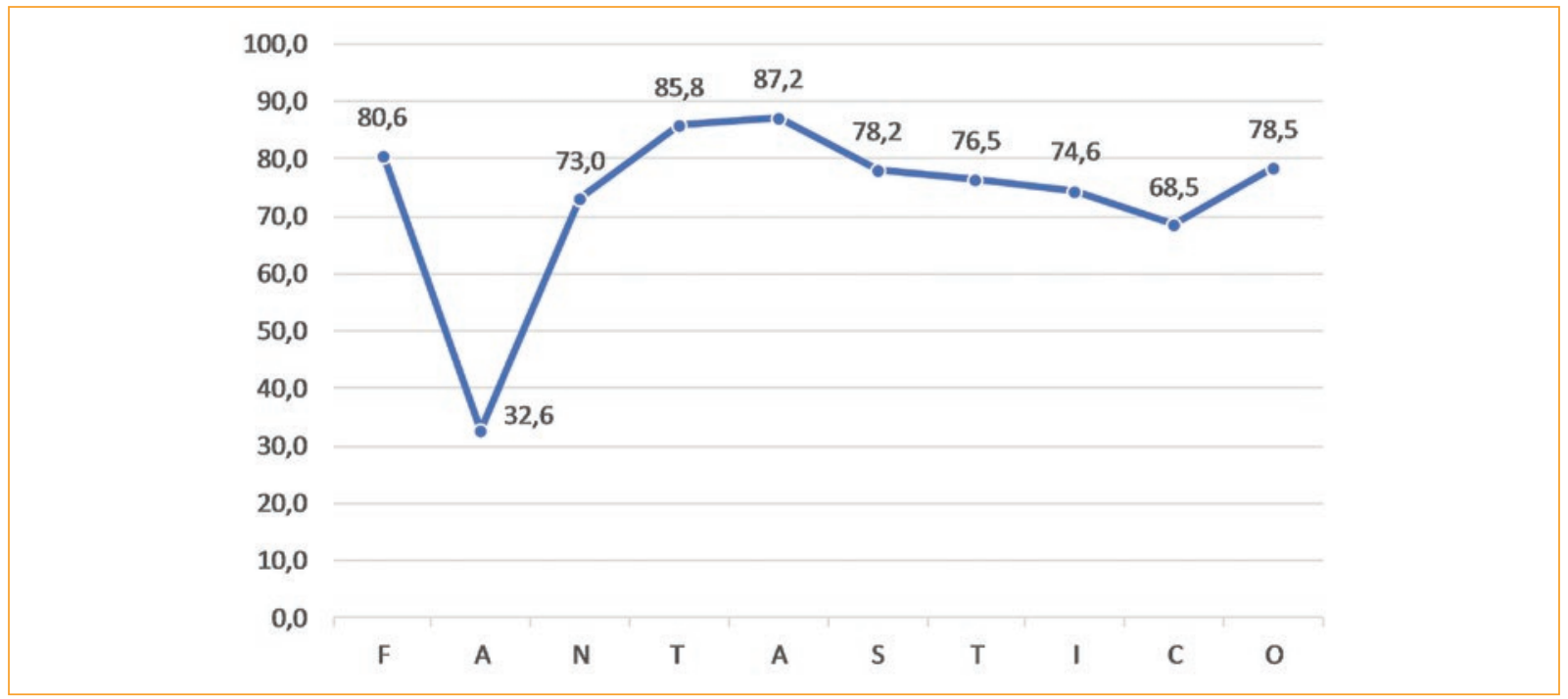

Figure 1. Trend by lifestyles dimensions (Bogotá, Colombia; $n=149$ ). The trends of each of the scales of the FANTASTIC instrument are shown, which assesses the lifestyle of children. The data show the trend for each of the scales based on descriptive statistics (percentages).

F: family and friends, A: physical and social activity, N: nutrition, T: toxicity A: alcohol, S: sleep and stress,

T: personality type and activities, I: inner image, C: health and sexuality control; 0: order.

Table 3. Correlation between psychological profiles and refractive errors

\begin{tabular}{|c|c|c|c|c|c|c|c|}
\hline & \multirow{2}{*}{\multicolumn{2}{|c|}{$\begin{array}{c}\text { Emmetropia } \\
\qquad(n=71)\end{array}$}} & \multirow{2}{*}{\multicolumn{2}{|c|}{$\begin{array}{c}\text { Hyperopia } \\
(n=50)\end{array}$}} & \multirow{2}{*}{\multicolumn{2}{|c|}{$\begin{array}{c}\text { Astigmatism } \\
(n=28)\end{array}$}} & \multirow[t]{3}{*}{ p-value* } \\
\hline & & & & & & & \\
\hline & M/SD & $95 \%$ CI & M/SD & $95 \%$ CI & M/SD & $95 \% \mathrm{Cl}$ & \\
\hline \multicolumn{8}{|c|}{ Scales } \\
\hline A: reserved-open & $5.41 \pm 1.924$ & $(4.95-5,86)$ & $5.92 \pm 2.098$ & $(5.32-5.86)$ & $6.04 \pm 2.151$ & $(5.20-6.87)$ & 0.247 \\
\hline D: calm-excitable & $4.55 \pm 1.918$ & $(4.10-5.00)$ & $4.82 \pm 2.077$ & $(4.23-5.41)$ & $4.82 \pm 1.887$ & $(4.09-5.55)$ & 0.703 \\
\hline E: submissive-dominant & $4.92 \pm 1.998$ & $(4.44-5.39)$ & $4.54 \pm 2.022$ & $(3.97-5.11)$ & $5.11 \pm 1.685$ & $(4.45-5.76)$ & 0.408 \\
\hline F: sober-enthusiastic & $5.54 \pm 1.747$ & $(5.12-5.95)$ & $5.30 \pm 1.619$ & $(4.84-5.76)$ & $6.00 \pm 2.091$ & $(5.19-6.81)$ & 0.251 \\
\hline $\mathrm{H}$ : shy-outgoing & $5.15 \pm 1.555$ & $(4.79-5.52)$ & $5.26 \pm 2.048$ & $(4.68-5.84)$ & $5.79 \pm 1.424$ & $(5.23-6.34)$ & 0.253 \\
\hline $\mathrm{J}$ : self-assured-hesitant & $5.59 \pm 1.745$ & $(5.18-6.00)$ & $6.22 \pm 1.753$ & $(5.72-6.72)$ & $5.04 \pm 1.915$ & $(4.29-5.78)$ & 0.017 \\
\hline 0 : serene-apprehensive & $5.99 \pm 1.840$ & $(5.53-6.42)$ & $5.86 \pm 2.129$ & $(5.26-6.46)$ & $5.86 \pm 1.779$ & $(5.17-6.55)$ & 0.923 \\
\hline Q4: relaxed-tense & $5.39 \pm 1.938$ & $(4.94-5.85)$ & $5.24 \pm 1.901$ & $(4.70-5.78)$ & $4.64 \pm 1.850$ & $(3.93-5.36)$ & 0.212 \\
\hline \multicolumn{8}{|c|}{ Second-order factors } \\
\hline Ql: adjustment-anxiety & $5.94 \pm 1.851$ & $(5.51-6.38)$ & $6.20 \pm 1.972$ & $(5.65-6.75)$ & $5.50 \pm 1.528$ & $(4.91-6.09)$ & 0.269 \\
\hline QII: introversion-extraversion & $6.52 \pm 1.847$ & $(5.18-6.06)$ & $5.96 \pm 1.795$ & $(5.45-6.47)$ & $5.71 \pm 1.560$ & $(5.11-6.32)$ & 0.582 \\
\hline
\end{tabular}

*ANOVA analysis of variance.

the boys and girls with an adequate nutritional status and good lifestyles belonged to the groups of emmetropia and RE. Regarding personality traits, it was evidenced that the majority of part boys and girls had average characteristics that allow their adaptability to the school environment, without statistically significant differences (Table 4). 
Table 4. Correlation of study variables with refractive errors (Bogotá, Colombia; $n=149$ )

\begin{tabular}{|c|c|c|c|c|c|}
\hline & & Emmetropia & Hyperopia & Astigmatism & \multirow[t]{2}{*}{ p-value* } \\
\hline & & \multicolumn{3}{|c|}{$n(\%)$} & \\
\hline \multirow[t]{5}{*}{ Nutritional diagnosis } & Adequate & $47(66.2)$ & $31(62.0)$ & $19(67.9)$ & \multirow[t]{5}{*}{0.912} \\
\hline & Obesity & $5(7.0)$ & $3(6.0)$ & $1(3.6)$ & \\
\hline & Malnourishment risk & $7(9.9)$ & $7(14.0)$ & $5(17.9)$ & \\
\hline & Delayed growth risk & $1(1.4)$ & 0 & 0 & \\
\hline & Overweight & $11(15.5)$ & $9(18.0)$ & $3(10.7)$ & \\
\hline \multirow[t]{4}{*}{ Lifestyles } & Fantastic & $9(12.7)$ & $2(4.0)$ & $6(21.4)$ & \multirow[t]{4}{*}{0.371} \\
\hline & Good & $38(53.5)$ & $30(60.0)$ & $14(50.0)$ & \\
\hline & Adequate & $21(29.6)$ & $14(28.0)$ & $7(25.0)$ & \\
\hline & Low & $3(4.2)$ & $4(8.0)$ & $1(3.6)$ & \\
\hline \multicolumn{6}{|c|}{ Personality trait. Second-order factors } \\
\hline \multirow[t]{3}{*}{ QI } & Flexible & $23(32.4)$ & $9(18.0)$ & $6(21.4)$ & \multirow[t]{3}{*}{0.425} \\
\hline & Anxiety & $20(28.2)$ & $18(36.0)$ & $8(28.6)$ & \\
\hline & Average & $28(39.4)$ & $23(46.0)$ & $14(50.0)$ & \\
\hline \multirow[t]{3}{*}{ Oll } & Extrovert & $15(21.1)$ & $16(32.0)$ & $11(39.3)$ & \multirow[t]{3}{*}{0.150} \\
\hline & Introvert & $16(22.5)$ & $14(28.0)$ & $3(10.7)$ & \\
\hline & Average & $40(56.3)$ & $20(40.0)$ & $14(50.0)$ & \\
\hline
\end{tabular}

*Pearson's Chi Square.

\section{Discussion}

A large number of studies identifying risk factors associated with myopia in children have been performed; however, there are few studies about hyperopia and astigmatism. This can be due to the epidemiological behavior of RE, since in regions with more publications, the prevalence of myopia is higher than in the region of the Americas (in our study, this determined the exclusion of a single case of myopia).

In this sense, the estimated prevalence of RE worldwide in children with myopia, hyperopia, and astigmatism is of $11.7,4.6$, and $14.9 \%$, respectively, and specifically the prevalence of hyperopia and astigmatism is higher in the Americas region compared to the global prevalence $(14.3 \% \text { and } 27.2 \%)^{1}$. In Colombia, reports of prevalence with the use of cyclopegic refraction have not been reported; however, in 2000, the National Institute of Health reported a prevalence of hyperopia of $59.2 \%$, astigmatism $28.2 \%$, myopia $4.0 \%$ and emmetropia $9.0 \%$ in a population from 5 to 14 years old ${ }^{17}$.
We found that the prevalence of hyperopia was higher compared to that of astigmatism, which differs from the trend in the European and Asian continents and is consistent with the American region, where these RE are identified as the most frequent visual disturbances in children, associated with possible genetic and environmental factors typical of the region. Even so, we also identified a decrease in the frequency of hyperopia with increasing age, maintaining the trend towards emmetropization, due to changes in corneal curvature, axial length and lens power after 6 years old ${ }^{18}$, which allows us to deduce an adequate emmetropization process in our population. Regarding astigmatism, although the prevalence is lower and similar compared to other results, ${ }^{19}$ its tendency to increase with age is significant in our population, therefore, identifying astigmatism in the pediatric population is essential due to the risk of amblyopia, especially in high astigmatisms, and due to the association reported by the literature between astigmatism and the development of myopia ${ }^{20}$. On the other hand, although the causes of astigmatism 
are not clear, genetic factors, pressure on the eyelids, extraocular muscle tension, gestational age and low birth weight are conditions that have a role in the development of astigmatism, and should be taken into account, as well as failures in emmetropization and socio-environmental factors ${ }^{18}$.

The visual health of our population was characterized by a higher prevalence of hyperopia in boys and astigmatism in girls, with an increase in astigmatism in the general population and a decrease in hyperopia at older ages. Although no association was found between gender and RE, as in Pi's study, related research has found a greater probability of hyperopia in girls ${ }^{21-24}$, which differs with our results, making necessary in subsequent studies to emphasize the behavioral differences by sex, in terms of socio-environmental and cultural factors, as well as study habits.

Regarding sociodemographic aspects, a higher prevalence of ametropia was found in socially unfavorable conditions. Tarczy-Hornoch, et al., identified an association of lack of health security and a lower family educational level with decreased vision ${ }^{25}$. In our study, no conclusive results can be drawn against these specific variables due to the social homogeneity of the population; however, it is possible to contextualize the global differences between emmetropic children and children with RE from the analysis of nutritional aspects and lifestyles such as indirect parameters of the social situation of our children.

The results regarding nutritional status showed statistically significant differences between boys and girls with emmetropia and RE in relation to height, without being clearly defined whether nutritional status is a differentiating factor, taking into account the global parameters of nutritional status. The literature has reported the relationship between malnutrition and visual disturbances; however, the relationship of height with $R E$ is not yet clearly documented. It should be noted that, in the present study, hyperopic and astigmatic children had a lower height compared to children with emmetropia, an aspect that must be further evaluated from adjusted analysis models.

Regarding nutritional habits and lifestyles, the limited consumption of fruits and vegetables and the differences in dairy consumption in children with ametropia was significant, as were the differences in sugar consumption between ametropic and emmetropic children. In general, emmetropic children consume fewer portions of sugar than children with ametropia, especially hyperopic children. The literature suggests that high carbohydrate diets can cause permanent changes in the development and progression of RE, particularly during periods of childhood development, and this should be analyzed in greater depth. According to You, there is no evidence linking the consumption of fruits and vegetables with $\mathrm{RE}^{26}$. Even so, it should be noted that our study population belongs to areas classified by poverty indices that have access to community food services. In this sense, it is likely that their diet during the school day includes vitamin D-enriched foods and dairy, essential for the metabolism of calcium and phosphate, which determines the subsequent dopaminergic activity in the retina, sclera and eyeball growth $^{27-29}$. In addition, limited access to fast food due to the economic conditions of the population becomes a protective factor, largely due to the preservation of an adequate nutritional state related to the low consumption of animal fat and simple carbohydrates, reported by Terasaki, et al. as foods that trigger hypercholesterolemia and insulinemia associated with axial length and subsequent elongation of collagen fibrils in the sclera ${ }^{30}$.

Regarding rest and sleep habits, we identified statistically significant differences in the average hours of sleep in children with ametropia. Astigmatic children had less hours of rest compared to hyperopic children. In this regard, the literature has reported that children with less than 7 hours of sleep per day have a 3.37 times greater risk of myopia than those with more than 9 hours of sleep ${ }^{31,32}$; however, Sensaki, et al. concluded that there is no relationship between hours of sleep and RE in 3-year-old children ${ }^{26,33}$.

On the other hand, hyperopic children had higher habits of exposure to television screens and near-distance activities related to reading and drawing. The results regarding the impact of these habits in children are not yet clear. In studies with children in Japan, the analyses comparing groups with and without RE were not significantly different; however, data on progression towards myopia have been reported in Spanish studies of young populations ${ }^{34}$.

Regarding toxic exposure, we identified a high frequency and early onset of alcohol and tobacco use. The concern regarding the vulnerability of the population should be a reason for intervention, but regarding $\mathrm{RE}$ there is no significant association, although prenatal exposure and subsequent development of amblyopia are clearly related ${ }^{25,34}$.

Physical and recreational activities in general were limited in our population. This is probably the consequence of limited access of our children to sports due to their socioeconomic and recreational infrastructure 
condition, which implies less participation in outdoor activities and, therefore, a sedentary lifestyle. In this regard, the relationship between physical activity and $\mathrm{RE}$ is not yet clear; however, Huang, et al. ${ }^{34}$ reported a higher prevalence of disorders such as myopia due to less outdoor activities ${ }^{34}$, but this is not clear in the case of hyperopia or astigmatism. In this sense, the interest for controlling the repercussions of RE and the absence of physical activity should focus on the analysis of the comorbidity of non-communicable diseases with visual loss in later life courses.

The results of RE and personality traits showed emotional stability in a high percentage of the population, showing children with adequate emotional responses, adapted to the school environment, with positive and constructive behaviors. Even so, statistically significant differences were found in personality ranges related to anxiety control among children with astigmatism and hyperopia, and the latter were of special interest based on our findings for their traits of being more individualistic, with motor repression and disdainful with others compared to children with $\mathrm{J}_{-}$, on the doubt-safety scale, which has also been reported by Akcay, et al. in adults ${ }^{5}$. According to this author, people with RE are less compassionate and more self-centered, and specifically hyperopic children may have weak characteristics regarding empathy ${ }^{5}$, especially due to the development of a demanding personality. Uretme, et al. relate these personality types to accommodation processes to erase images and the subsequent development of esotropia, and compare them with children who develop ametropic amblyopia, who retain demanding, perfectionist, and prescriptive traits, also observed in children with hyperopia ${ }^{35}$. In contrast, children with astigmatism demonstrate more empathetic characteristics.

\section{Conclusion}

The global analysis of the variables in our sample did not show statistically significant differences between ametropia and emmetropia regarding the evaluated factors: nutrition, physical activity and personality traits. However, this study can be considered a starting point to identify the prevalence and analyze the predisposing conditions of RE, especially in hyperopic children, in whom we observe particular results in relation to lifestyles, personality traits and emotional stability. In our study population, astigmatism tends to increase with age, so early identification of this RE in children is essential to decrease the risk of developing amblyopia.

\section{Limitations}

Our study had the following limitations. First, the sample size probably did not allow finding an association between the multiple variables analyzed. Second, the variables that analyze the nutritional and psychological aspects are very wide, so they must be defined in the future for their respective analysis. Third, we did not use an auto refractometer for refraction, which was performed only by retinoscopy. Fourth, since it was a cross-sectional study, it was not possible to determine the age of onset of anisometropia or the type of esotropia that can be associated with the Latin American population. Fifth, the analysis of risk factors should be approached through longitudinal studies to identify the risk condition and the appearance of $R E$ in early stages.

\section{Conflicts of interest}

The authors declare no conflicts of interest.

\section{Funding}

This research was approved by the Ethics Committee of the Antonio Nariño University in the city of Bogotá, Colombia, under protocol number 2017226.

\section{Ethical disclosures}

This study adheres to what is established for research in humans in accordance with the World Medical Association and the Declaration of Helsinki, and by the Resolution 8430 of 1993 of the Ministry of Health of the Republic of Colombia that establishes the considerations related to the investigation in adults and minors. The study was approved by the Ethics Committee of the Antonio Nariño University in the city of Bogotá, Colombia, under protocol number 2017226. Likewise, it was presented and approved by the directives of a school located in the town of Ciudad Bolívar in Bogotá. The data collection procedures were carried out with the prior informed consent of parents and caregivers and the informed assent of children with literacy skills.

Protection of human and animal subjects. The authors declare that the procedures carried out in the investigation were compliant with the standards for 
research in humans in accordance with the World Medical Association and the Declaration of Helsinki.

Confidentiality. The authors acknowledge that the data of the study participants were treated confidentially, according to institutional protocols.

Privacy. The authors have obtained the informed consent of parents and caregivers of the study population. The documents are in the custody of the correspondence author.

\section{References}

1. Hashemi H, Fotouhi A, Yekta A, Pakzad R, Ostadimoghaddam H, Khabazkhoob M. Global and regional estimates of prevalence of refractive errors: Systematic review and meta-analysis. J Curr Ophthalmol. 2018;30(1):3-22.

2. Rodruguez, I. Bartolomé FP, Ortiz MU, Villalobos PA, Rodríguez IU, Vallecilla MB, Cueto LF, et al. Estudio de la relación entre miopía y personalidad. Arch Soc Esp Oftalmol. 2015;90(8):365-72.

3. Hu H, Dai J, Chen M, Chen L, Jiang L, Lin R, et al. Effect of astigmatism on refraction in children with high hyperopia. Drug Discov Ther 2017;10(6):323-8.

4. Van De Berg R, Dirani M, Chen CY, Haslam N, Baird PN. Myopia and personality: The genes in myopia (GEM) personality study. Investig Ophthalmol Vis Sci. 2008;49(3):882-6.

5. Akcay EK, Canan F, Simavli H, Dal D, Yalniz H, Ugurlu N, et al. Effect of refractive error on temperament and character properties. Int J Ophthalmol. 2015;8(1):72-6.

6. Loaiza DPB, Álvarez CV, Vargas LJ. Validación de contenido y adaptación del cuestionario Fantastico por técnica Delphi. Salud Uninorte. 2015;31(2):214-27.

7. Tideman JWL, Polling JR, Hofman A, Jaddoe VW, Mackenbach JP, Klaver CC, et al. Environmental factors explain socioeconomic prevalence differences in myopia in 6-year-old children. $\mathrm{Br} \mathrm{J}$ Ophthalmol. 2018;102(2):243-7.

8. Ip JM, Saw SM, Rose KA, Morgan IG, Kifley A, Wang JJ, et al. Role of near work in myopia: Findings in a sample of Australian school children. Investig Ophthalmol Vis Sci. 2008;49(7):2903-10.

9. Organización Mundial de la Salud. Salud ocular universal. Un plan de acción mundial para 2014-2019. Madrid, España; 2014. [citado 5 de julio de 2019]. Disponible en: https://www.who.int/blindness/AP2014_19_Spanish.pdf?ua $=1$

10. Ministerio de Salud y Protección Social. Guía de Práctica Clínica para la prevención, la detección temprana, el diagnóstico, el tratamiento y el seguimiento de la ambliopía en menores de 18 años. Bogotá, Colombia; 2016. [citado 3 de julio de 2019]. Disponible en: http://gpc.minsalud.gov. co/gpc_sites/Repositorio/Conv_637/GPC_d_refractivos/gpc_d_refractivos.aspx

11. Castagno VD, Fassa AG, Vilela MAP, Meucci RD, Resende DPM. Moderate hyperopia prevalence and associated factors among elementary school students. Cien Saude Colet [Internet]. 2015;20(5):1449-8.

12. Lizama Lefno A. Multidisciplinariedad en el Manejo de Enfermedades Crónicas. An la Fac Med. 2016;77(3):263-7.

13. World Health Organization. Assessment of the prevalence of visual impairment attributable to refractive error or other causes in school children. Protocol and Manual. Geneve. 2007. [citado 7 de julio de 2019] Disponible en: https://www.who.int/blindness/causes/RESCProtocol.pdf
14. Ministerio de Salud y Protección Social. Resolución 2465 de 2016. Bogotá, Colombia; 2016. [citado Julio 15 de 2019] Disponible en: https://www. minsalud.gov.co/Normatividad_Nuevo/Forms/DispForm.aspx?ID=4909

15. Betancurth Loaiza DP, Vélez Álvarez C, Jurado Vargas L. Validation and adaptation of the Fantastico questionnaire by Delphi technique. Salud Uninorte. 2015 May;31(2):214-27.

16. Coan RW, Cattell RB. Cuestionario de personalidad para niños. TEA Ediciones, $8^{\text {th }}$ ed. Madrid; 2013. $47 \mathrm{p}$.

17. Hernández Luna CP, Barrera Santos DC, Guiza Segura C, Rodríguez Malagón JP, Montaña Ludeman WE, et al. Estudio de prevalencia en salud visual en una población escolar de Bogotá, Colombia, 2000. Cienc Tecnol para la Salud Vis y Ocul. 2003;0(1):11-23.

18. Castro Piña S, Rey Rodríguez DV, Álvarez Peregrina C, Moreno Montoya J. Proceso de emetropización y desarrollo de miopía en escolares. Cienc Tecnol para la Salud Vis y Ocul. 2018:16(1):87-93.

19. Giordano L, Friedman DS, Repka MX, Katz J, Ibironke J, Hawes P, et al. Prevalence of Refractive Error among Preschool Children in an Urban Population: The Baltimore Pediatric Eye Disease Study. Ophthalmology. 2009;116(4):739-46.

20. Tong L, Saw SM, Carkeet A, Chan WY, Wu HM, Tan D. Prevalence rates and epidemiological risk factors for astigmatism in Singapore school children. Optom Vis Sci. 2002;79(9):606-13.

21. Guo X, Fu M, Ding X, Morgan IG, Zeng Y, He M. Significant Axial Elongation with Minimal Change in Refraction in 3- to 6-Year-Old Chinese Preschoolers: The Shenzhen Kindergarten Eye Study. Ophthalmology. 2017;124(12):1826-38.

22. Guo Y, Liu LJ, Tang $P, L v Y Y$, Feng $Y, X u L$, et al. Outdoor activity and myopia progression in 4-year follow-up of Chinese primary school children: The Beijing Children Eye Study. PLoS One. 2017;12(4):1-14.

23. Lau JK, Vincent SJ, Collins MJ, Cheung SW, Cho P. Ocular higher-order aberrations and axial eye growth in young Hong Kong children. Sci Rep. 2018;8(1):2-11.

24. Pi LH, Chen L, Liu Q, Ke N, Fang J, Zhang S, et al. Refractive status and prevalence of refractive errors in suburban school-age children. Int J Med Sci. 2010;7(6):342-53.

25. Tarczy-Hornoch K, Varma R, Cotter SA, McKean-Cowdin R, Lin JH, Borchert MS, et al. Risk Factors for Astigmatism in Preschool Children. Ophthalmology. 2011;118(11)

26. You QS, Wu LJ, Duan JL, Luo YX, Liu LJ, Li X, et al. Factors Associated with Myopia in School Children in China: The Beijing Childhood Eye Study. Baird P, editor. PLoS One. 2012 Dec 27;7(12)

27. Choi JA, Han K, Park Y-M, La TY. Low serum 25-hydroxyvitamin D is associated with myopia in Korean adolescents. Invest Ophthalmol Vis Sci. 2014 Apr;55(4):2041-7.

28. Ramamurthy D, Lin Chua SY, Saw S-M. A review of environmental risk factors for myopia during early life, childhood and adolescence. Clin Exp Optom. 2015 Nov;98(6):497-506.

29. Wilcox T, Hirshkowitz A. Boas D. The effect of color priming on infant brain and behavior. Neuroimage. 2015:85(0 1):1-27.

30. Terasaki H, Yamashita T, Yoshihara N, Kii Y, Sakamoto T. Association of lifestyle and body structure to ocular axial length in Japanese elementary school children. BMC Ophthalmol. 2017;17(1):1-7.

31. Jee D, Morgan IG, Kim EC. Inverse relationship between sleep duration and myopia. Acta Ophthalmol. 2016;94(3):e204-10.

32. Gong Y, Zhang X, Tian D, Wang D, Xiao G. Parental myopia, near work, hours of sleep and myopia in Chinese children. Health (Irvine Calif). 2014:06(01):64-70.

33. Sensaki S, Sabanayagam C, Chua S, Htoon HM, Broekman BFP, Thiam DGY, et al. Sleep Duration in Infants Was Not Associated With Myopia at 3 Years. Asia-Pacific J Ophthalmol. 2018;7(2):102-8.

34. Huang L, Kawasaki H, Yasuda R, Sakai R. Relationship between Visual Acuity and Lifestyle: A Cross-Sectional Study in Japanese Children. Hiroshima J Med Sci. 2018;67(4):1-2.

35. Uretmen O, Kesikci H, Erermis S, Kose S, Pamukcu K, Aydin C. Could personality traits modify the response to uncorrected high hyperopia? J AAPOS. 2005;9(5):480-4. 